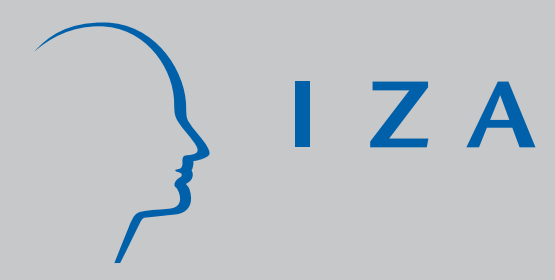

IZA DP No. 887

Transparency and Reciprocal Behavior in Employment Relations

Bernd Irlenbusch

Dirk Sliwka

October 2003 


\title{
Transparency and Reciprocal Behavior in Employment Relations
}

\author{
Bernd Irlenbusch \\ University of Erfurt \\ Dirk Sliwka \\ University of Bonn and IZA Bonn
}

Discussion Paper No. 887

October 2003

\author{
IZA \\ P.O. Box 7240 \\ D-53072 Bonn \\ Germany \\ Tel.: +49-228-3894-0 \\ Fax: +49-228-3894-210 \\ Email: iza@iza.org
}

This Discussion Paper is issued within the framework of IZA's research area General Labor Economics. Any opinions expressed here are those of the author(s) and not those of the institute. Research disseminated by IZA may include views on policy, but the institute itself takes no institutional policy positions.

The Institute for the Study of Labor (IZA) in Bonn is a local and virtual international research center and a place of communication between science, politics and business. IZA is an independent, nonprofit limited liability company (Gesellschaft mit beschränkter Haftung) supported by Deutsche Post World Net. The center is associated with the University of Bonn and offers a stimulating research environment through its research networks, research support, and visitors and doctoral programs. IZA engages in (i) original and internationally competitive research in all fields of labor economics, (ii) development of policy concepts, and (iii) dissemination of research results and concepts to the interested public. The current research program deals with (1) mobility and flexibility of labor, (2) internationalization of labor markets, (3) welfare state and labor market, (4) labor markets in transition countries, (5) the future of labor, (6) evaluation of labor market policies and projects and (7) general labor economics.

IZA Discussion Papers often represent preliminary work and are circulated to encourage discussion. Citation of such a paper should account for its provisional character. A revised version may be available on the IZA website (www.iza.org) or directly from the author. 
IZA Discussion Paper No. 887

October 2003

\section{ABSTRACT}

\section{Transparency and Reciprocal Behavior in Employment Relations*}

The impact of transparency on the extent of reciprocal behavior is investigated in a simple repeated gift exchange experiment, where principals set wages and agents respond by choosing effort levels. In addition to the efforts the principals' payoffs are determined by a random component. It is shown that direct reciprocal behavior is much stronger in a more transparent situation where efforts are revealed to the principals. However, there is no significant impact of transparency on average effort as non-transparency leads to a stronger diversity in behavioral patterns such that at the same time the frequency of very low and very large effort levels increases.

JEL Classification: C72, C91, J33

Keywords: transparency, reciprocity, reputation, gift exchange, inequity aversion

Corresponding author:

Dirk Sliwka

Betriebswirtschaftliche Abteilung II

University of Bonn

Adenauerallee 24-42

53113 Bonn

Germany

Tel.: +49 228739214

Fax: +49228739210

Email: dirk.sliwka@uni-bonn.de

\footnotetext{
* We thank two anonymous referees and Simon Gächter for valuable comments. Financial support by the Deutsche Forschungsgemeinschaft through grant KR2077/2-1 and the European Union through the EU-TMR Research Network ENDEAR (FMRX-CT98-0238) is gratefully acknowledged.
} 


\section{Introduction}

A large and steadily growing literature has pointed out that many agents are, to some extent, guided by the social norm of reciprocity and fairness concerns. In particular, this has been examined in simple experimental gift exchange games where a principal offers a wage to an agent, who then can respond by choosing a costly action ("effort") raising the principal's utility. Typically the gift exchange situation is modeled such that the principal perfectly observes the effort the agent is willing to exert in response. Unfortunately, for most employment relationships this assumption is unwarranted because in general the principal can at best only observe the output which, however, is determined not solely by effort but also by unobservable random events. In such a situation it is far from clear whether the agent still reciprocates on generous wages since he may "hide" his low effort choice behind the unobservable random events and take the latter as an excuse. This conjecture is supported by observations known from the ultimatum game literature which indicate that under asymmetric information players take advantage of other's uncertainty (Mitzkewitz and Nagel 1993; Güth, Huck, and Ockenfels 1996; Kagel, Kim, and Moser 1996; Huck 1999). If the principal anticipates such behavior of the agent, severe doubts arise whether offering high wages and trusting in reciprocity really pays off. In this paper we try to shed light on this up to now unanswered but nevertheless quite important question. We report the results of a gift exchange experiment, which to our knowledge is the first one that dropps the assumption of perfect transparency of the agents effort choice.

Agency relations, in which principal and agent have different individual objectives, are pervasive and quite frequently the principal cannot easily determine whether the agent takes appropriate actions in pursuit of the principal's goals or follows self-interested misbehavior. Thus, the hidden action assumption is a key feature of most principal agent models, see e.g. Grossman and Hart (1983), Hart and Holmström (1987), or Sappington (1991). However, the influence of social norms or social preferences is widely unexplored in agency relations with hidden action possibilities. Note that the question in how far actors succeed in relying on reciprocal behavior in the presence of hidden action at its very heart is an empirical question. Since actions which are not in the interest of the principal are generally secretly performed by the agent, field data on hidden action behavior is quite difficult to obtain. Therefore, in this study we opt for an investigation based on a controlled experiment. An experiment has the advantage that one can compare different clear cut institutional designs, i.e. one is able to sharply separate different institutional design features and analyse their influence on actual behavior. A further advantage is that experimental data is not perturbed by various interferences which is likely to be the case with field data from real world situations.

The importance of fairness considerations and reciprocal behavior in mutual ex- 
change relationships has been shown in numerous studies, e.g. Fehr, Kirchsteiger, and Riedl (1993), Berg, Dickhaut, and McCabe (1995), Fehr, Gächter and Kirchsteiger (1997), Abbink, Irlenbusch, and Renner (2000), Dufwenberg and Gneezy (2000), Fehr and Gächter (2000), Heijden, Nelissen, Poters and Verbon (2001), or Clark and Sefton (2001). ${ }^{1}$ In simple experimental gift exchange games a principal offers a wage to an agent, who then responds by exerting costly effort. The latter raises the principal's payoff. Whereas standard game theory predicts that the agent shows no effort at all and the principal is in turn not willing to pay positive wages, many experiments have shown that subjects behave differently. In general it is observed that a significant fraction of participants pay positive wages and exert positive effort levels. Several factors which influence the inclination for reciprocal behavior have been identified in various experimental settings, for example "hot versus cold" decisions (Brandts and Charness 1998), or intentions (Charness 2000; Falk, Fehr, Fischbacher 2000; Charness (forthcoming)). Moreover, when a gift exchange game is played repeatedly, in addition to "pure" reciprocity it is observed that agents imitate such behavior in early periods intending to build up a reputation and therefore to achieve higher wage payments in the future (Gächter and Falk 2002).

The aim of the current paper is to analyze the impact of transparency on the evolution of reciprocal behavior. We compare two treatments. Both treatments consist of several periods in each of which a principal sets a wage, that is directly transferred to an agent. The agent may respond by choosing a costly effort level. The principal's payoff is the sum of the agents effort and a random component. In the first "revealed effort" treatment the principal perfectly learns both components of her payoff - the effort as well as the value of the random component. In the second "hidden effort" treatment the principal is only informed about her payoff. Furthermore, in contrast to all other gift exchange experiments we are aware of, in our treatments agents are allowed to exert inefficiently high effort levels, i.e. the cost function is chosen such that it is not efficient to choose the highest possible effort level.

\section{Experimental Design and Procedure}

The experiment was conducted in the Laboratorium für experimentelle Wirtschaftsforschung $(e L a b)$ at the University of Erfurt. In total 48 students participated most of them were enrolled in the Faculty of Law, Economics, and the Social Sciences. Two treatments were implemented according to the two settings proposed in the previous section. For each of the two treatments - the hidden effort treatment

\footnotetext{
${ }^{1}$ Note that not all of these experimental studies frame their settings as a gift exchange game which points to the fact that the norm of reciprocity affects behavior in a wide range of different contexts.
} 
and the revealed effort treatment - we conducted one session with 24 participants each. A session consisted of 20 identical periods and lasted for about 1 hour. During the session payoffs were given in our fictitious experimental currency "Taler". After a session payoffs were converted to DM and paid in cash with an exchange rate of $1.5 \mathrm{DM}(\approx .77$ Euro) for 100 Taler.

At the outset of a session the instructions were handed out and read by the experimenters. In addition the participants were advised how to use the experimental software. ${ }^{2}$ In order to reduce the influence of uncontrollable connotations the strategic situation of the experiment was presented in completely neutral terms. Terms like "principal" or "agent" were avoided, instead the roles were referred to as players of type A (principals) and type B (agents). We spoke of "transfers" instead of "wages" and instead of "effort" a "number" could be selected. After the instructions were read all 24 participants took seat in a cubicle randomly assigned. The computer software matched participants into pairs randomly and anonymously. Half of the participants were assigned the role of a principal and the other half the role of an agent. Pairs and roles were fixed during the whole experiment. Thus, we collected twelve independent observations per session. Communication - other than over the experimental software - was not allowed.

In the beginning of each period each principal chooses a wage level chosen from the integer set $\{0, \ldots, 45\}$ which was directly transferred from her account to that of the agent assigned to her. After this the respective agent had to choose an effort level from the integer set $\{0, \ldots, 25\}$. Then the output was determined by adding a randomly drawn number to the effort level. Each of the numbers in $\{0, \ldots, 20\}$ could be drawn with the same probability. Thus, the total payoff for the principal was defined as output minus wage. The total agent's payoff was the wage minus the cost for the chosen effort level. The cost function for agents' efforts is given in the appendix. We handed out the cost table as well as the graphical illustration of the cost function to all participants. As can be derived from the cost table the efficient outcome is achieved at an effort level of 12 . While at all effort levels less than 12 the marginal cost of one additional effort unit is less than one, it is higher than one at effort levels above 12. In both treatments the agent learned the principal's payoff. In the hidden effort treatment the principal was only informed about her payoff without knowing the detailed composition. Note, however, that the principal can form some inference about the effort level, especially when the realized principal's payoff is close to the edges of the possible range of $\{0, \ldots, 45\}$. For example, if the principal's payoff exceeds 20 by an amount of $x>0$ the principal knows for sure that the agent has exerted an effort level which is at least as high as $x$. In the revealed

\footnotetext{
${ }^{2} \mathrm{~A}$ translation of the instruction sheet is given in the appendix - the original German text is available from the authors on request. The experimental software was developed by making use of the toolbox zTree (Fischbacher 1998).
} 
effort treatment in addition the principal got to know the exact values of the exerted effort level and the random component. ${ }^{3}$ This procedure was repeated 20 times with unchanged principal-agent pairs. Table 1 summarizes our experimental setting.

Table 1 : Experimental Design

\begin{tabular}{|c|c|c|}
\hline & "Hidden Effort & Revealed Effort \\
\hline \# independent observations & 12 & 12 \\
\hline Initial capital balance of principals & \multicolumn{2}{|c|}{50} \\
\hline Initial capital balance of agents & \multicolumn{2}{|c|}{50} \\
\hline \# rounds per session & \multicolumn{2}{|c|}{20} \\
\hline Integer set of effort levels & \multicolumn{2}{|c|}{$0, \ldots, 25$} \\
\hline Integer set of random component & \multicolumn{2}{|c|}{$0, \ldots, 20$} \\
\hline Integer set of wages & \multicolumn{2}{|c|}{$0, \ldots, 45$} \\
\hline
\end{tabular}

\section{Hypotheses}

Under the standard assumptions of rationality and self-interest the theoretical predictions are very simple in both treatments. As the game is finitely repeated the agent will never exert positive effort levels and the principal will not pay positive wages in any subgame perfect equilibrium of the game.

However, as mentioned above this hypothesis has been rejected in numerous experimental studies. Hence, a second benchmark is set by the literature on reciprocal behavior. The social norm of reciprocity prescribes that agents reward kind acts by other agents (or punish unkind acts) even if it is costly for themselves. When formulating our hypotheses we should take the observation into account that the norm of reciprocity is a decisive guideline for behavior. Thus, in order to give our hypotheses a deeper theoretical backing, we analyse a simple repeated gift exchange game which we have added in the appendix. ${ }^{4}$ In this model we adopt the Fehr and Schmidt (1999) type approach to explain reciprocal behavior by assuming that some agents dislike inequity. ${ }^{5}$ Although this apporach does not model preferences

\footnotetext{
${ }^{3}$ Note that the situation of the principal does not differ to the extreme between treaments. While he exactly knows the effort choice in the revealed treatment he is not in complete darkness in the hidden treatment. If we were to find a difference in behavior between treatments this might even strengthen the results.

${ }^{4}$ We thank an anonymous referee for pointing in that direction.

${ }^{5}$ An alternative apporoach for modeling inequity aversion is proposed by Bolton and Ockenfels (2000).
} 
for intentional reciprocal behavior directly, it has been quite successful in being able to explain behavior in experiments. Inequity averse agents behave reciprocally for the following reason: Suppose that an agent has received a high wage. If he does not respond with a high effort level, the income arising from the deal would be distributed unevenly (to his advantage) and his utility would be reduced as he dislikes inequity. He may choose a high effort level to prevent this utility loss. Therefore a principal offers higher wages to agents if she believes that those agents are inequity averse. This provides an incentive even for selfish agents to build a reputation of being inequity averse.

However, we do not want to claim that inequity aversion is the sole driving force behind observed reciprocal behavior. Some authors have modeled preferences for direct reciprocal behavior. In these models, an agent's utility also depends on the material payoff of others. But whether they enjoy or dislike higher payoffs of others, depends on their beliefs on the kindness of the others' actions. This has for instance been done in Rabin (1993), Falk and Fischbacher (1999), or Dufwenberg and Kirchsteiger (1999). Indeed, Charness (forthcoming) experimentally observed that recipocal behavior is weaker when wages are set by an external process rather than beeing chosen by an employer, which would not be the case if inequity aversion is the sole explanation for reciprocal behavior. A similar observation has been made by Falk, Fehr, Fischbacher (2000). ${ }^{6}$

But in any case, we should expect that wages and efforts are positively correlated, i.e. the larger the wage the principal offers the higher is the effort level chosen by the agent. Furthermore, note that we should observe reciprocal behavior in both treatments. Although the strength of the reciprocal reaction may vary with the transparency of the situation, an agent behaving reciprocally and willing to reward a favour received from a principal should do this even if his response is not observed by this principal. Hence, we can formulate the following general hypothesis for both treatments:

\section{Hypothesis 1: Reciprocal Behavior}

There is a positive correlation between wages and effort levels in both treatments.

But given that there are some reciprocal players among the experimental subjects, the rational prediction changes. An agent who is believed to behave reciprocally will receive positive wage offers in the future. This in turn makes it attractive for a non-reciprocal agent to imitate a reciprocal one in early periods. Hence, agents should care to obtain a reputation for reciprocity. Gächter and Falk (2002) find ex-

\footnotetext{
${ }^{6}$ See also Charness and Rabin (2002) for an experimental comparison and a different modeling approach. Sethi and Somanathan (2003) survey the evolutionary game theoretic literature on the origins of reciprocal behavior.
} 
perimental evidence for this in a repeated gift exchange experiment with revealed effort levels. But at this point the extent of transparency should be of importance: when efforts are revealed a principal can directly observe whether an agent has responded to his positive wage offer by a positive effort level. When efforts are hidden, this is no longer possible. When having observed a positive payoff the principal cannot tell whether it was due to a high effort or mere luck. As it is harder for the principal to figure out whether an agent behaves reciprocally, it should be less attractive for an agent to imitate reciprocal behavior. In our model analyzed in the appendix we show that intransparency indeed reduces the possibility of achieving an equilibrium in which selfish agents try to build a reputation for reciprocal behavior due to inequity aversion. Hence, we conclude that we should observe weaker reciprocal behavior in the "hidden effort" case:

\section{Hypothesis 2: Transparency Strengthens Reciprocal Behavior}

The correlation between wages and effort levels should be stronger in the revealed effort treatment.

Furthermore, this hypothesis is supported by various observations from ultimatum games without repeated interaction, see for example Mitzkewitz and Nagel (1993), Güth, Huck, and Ockenfels (1996), Kagel, Kim, and Moser (1996), and Huck (1999). Contrary to our setting in these games reputation building is not possible. Nevertheless, it is found that the presence of asymmetric information tends to increase self-serving behavior.

If it is true that agents feel not obliged to follow the norm of reciprocity when effort is not directly observable, the overall gift exchange relationship is expected to work better in the more transparent environment. In fact in our model we obtain pooling equilibria in the transparent situation, in which the selfish agents imitate the inequity averse agents in the beginning, as this leads to higher wage offers later on. However, in the intransparent situation there are less incentives for the selfish agent to imitate reciprocal behavior. Thus, we expect that effort levels are higher in a transparent situation as agents cannot "hide" behind the random component.

\section{Hypothesis 3: Influence of Transparency}

Transparency should lead to higher effort levels.

Furthermore, as a principal can more easily condition wage payments on positive effort levels we expect that principals' profits are higher in the revealed effort setting. The impact of transparency on the agents' profits is less clear. On the one hand if the ability is unknown an agent exerting no effort at all is less easily detected and hence, may still receive positive wage offers by the principal. On the other hand, due to the same reason a principal may trust less in the reciprocal behavior of the 
agent, and therefore offer lower wages leading to lower profits for the agent.

\section{Results}

For an overview Table 2 shows the average efforts, wages and profits in both treatments.

Table 2: Average Efforts, Wages and Profits

\begin{tabular}{lll}
\hline \hline & Hidden Effort & Revealed Effort \\
\cline { 2 - 3 } Effort & 8.3 & 8.8 \\
Wage & 12.8 & 11.0 \\
Profit Principals & 5.5 & 7.8 \\
Profit Agents & 7.5 & 6.3 \\
\hline \hline
\end{tabular}

First, we want to measure the importance of the reciprocity norm- at this stage ignoring whether it may be "true" or pretended reciprocity. Therefore, we computed for each agent in each treatment a Pearson Correlation coefficient between his current wage and the effort exerted which are given in Table 3.

\begin{tabular}{ccccccccccccc} 
Table 3: Individual Pearson Correlation Coefficients between Effort and Wage \\
\hline \hline Rev. & .277 & .290 & .637 & .199 & .496 & .976 & .950 & .543 & .318 & .723 & .842 & .876
\end{tabular}

\begin{tabular}{llllllllllllll} 
Hid. & & .257 & .081 & .554 & .194 & -.024 & .282 & .137 & .749 & .131 & .037 & .587 & .431 \\
\hline \hline
\end{tabular}

Note that except for a single agent in the hidden ability treatment all correlation coefficients are positive indicating reciprocal behavior. Hence, for both treatments we can reject the null-hypothesis that positive and negative correlation coefficients are equally likely (1\%, Binomial Test, two-tailed). The average value of the individual correlation coefficient is 0.44 . We conclude:

\section{Observation 1:}

In both treatments reciprocal behavior by the agents is observed.

In the next step, we compare the extent of reciprocal behavior separately in both treatments. First, note that the average individual correlation is .285 in the hidden effort treatment and .595 in the revealed effort treatment. Hence, correlation is more than twice as strong when efforts are revealed. This difference is highly significant (1\% Mann-Whitney U-Test, two-tailed) yielding the following: 


\section{Observation 2:}

Reciprocal behavior is significantly stronger in the revealed effort treatment.

It is important to note that time trends may play a significant role in determining the correlation between effort and wage. ${ }^{7}$ Think for instance of a fictitious situation where principal and agent choose wage and effort only depending on the number of remaining periods. Then we would also observe a correlation between effort and wage, even when the wage has no direct impact on the agent's effort choice. To control for this, we computed partial correlation coefficients (see for instance Theil (1971, pp. 171-175)) for each principal agent pair to get a descriptive measure for the strength of time-invariant reciprocal behavior.

Note, however, that even if we observed only weak partial correlation between wage and effort conditional on the period, this would not necessarily imply that reciprocity is of no importance. Consider for instance a principal whose wage offers have a very strong negative correlation with the period in which the wage is offered. A reciprocal agent will then respond with declining effort levels even if his reaction function is time invariant. One can well construct examples where partial correlation gets quite small although a reciprocal reaction is the reason for the declining effort levels.

However, a positive partial correlation between effort and wages conditional on time shows that effort varies with wages even when we control for time trends. The partial correlation coefficents for each principal-agent pair in both treatments are given in table 4.

Table 4: Partial Correlations between Effort and Wage conditional on Period

\begin{tabular}{lcccccccccccc}
\hline \hline Rev. & -.038 & .375 & .411 & .307 & .288 & .930 & .944 & .087 & .307 & .657 & .752 & .771 \\
Hid. & .330 &.-.031 & .416 & -.069 & -.025 & .366 & -.014 & .795 & -.129 & .017 & .604 & .386 \\
\hline \hline
\end{tabular}

In the revealed effort treatment all coefficients except one are positive. Hence, we can reject the null hypothesis that no time invariant reciprocal behavior can be observed in this treatment (1\%, Binomial Test, two-tailed). However, we cannot reject this hypothesis for the hidden effort treatment as we observe 5 (weakly) negative values. Furthermore, the partial correlation coefficients are weakly significantly larger in the revealed than in the hidden effort treatment (Mann-Whitney U-Test, one-tailed, $p=5.5 \%$ ). These observations give some further backing to our previous observation that reciprocal behavior is stronger when efforts are revealed.

We mentioned two reasons why this could be the case. First, it should be easier to build a reputation for reciprocal behavior in the transparent situation. Hence,

\footnotetext{
${ }^{7}$ We thank an anonymous referee for pointing at this issue.
} 
agents act reciprocally as this leads to higher wage offers in future periods. But in addition, kind reactions by the agent are more directly perceived by the principal and this in itself may strengthen reciprocal behavior within a certain period. It is of course interesting to examine the importance of both explanations for our results. To do this, we investigated the heterogeneity of the participants by distinguishing "truely reciprocating agents" and "imitators of reciprocal behavior". We identified the truely reciprocating agents as those agents that received a positive wage in the last period and responded with a positive effort level. Hence, if there is an effect of transparency on "truely reciprocal behavior" we should observe a higher fraction of truely reciprocal agents in the revealed effort treatment. However, we found nearly the same fraction of truely reciprocal agents in both treatments: In the hidden effort treatment $36.36 \%$ of all agents that received a positive wage responded with a positive effort level and in the revealed effort treatment this fraction was $37.5 \%$. Hence, the direct perception of reciprocal behavior does not seem to be a relevant explanation for the stronger reciprocal behavior in the revealed setting than in the hidden setting. In contrast, building a reputation for reciprocity seems to be a more important behavioral motive.

But we are also interested in absolute effort levels. Given the previous results we should expect that effort levels are also higher in the revealed effort treatment as it appears to be easier to establish a reciprocal relationship if agents cannot "hide" behind the random component. However, a closer investigation yields a more complex and interesting pattern. Figure 1 shows that in the revealed effort treatment average effort is higher in return for wages under 25 , which is in line with our initial hypothesis. But for higher wages the average effort is lower in the revealed effort treatment! ${ }^{8}$ Furthermore, note that, as Figure 2 indicates, the frequency of such high wages is much higher in the hidden effort treatment than in the case where effort levels were revealed.

\footnotetext{
${ }^{8}$ This observation appears to be stable also over time. If one considers average effort per wage separately for rounds 1-10 and 11-20 one obtains similar figures as Figure 1. However, the figure for rounds 11-20 differs in the fact that wages above 29 are rarely observed.
} 


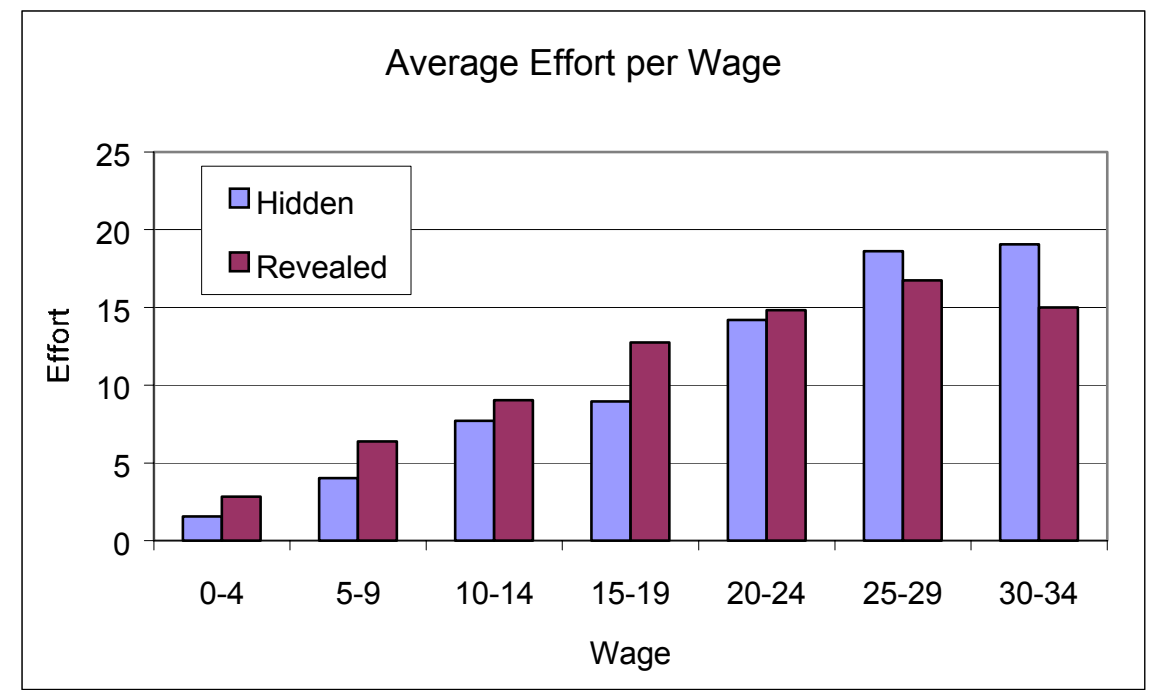

Figure 1: Average Effort per Wage in both Treatments

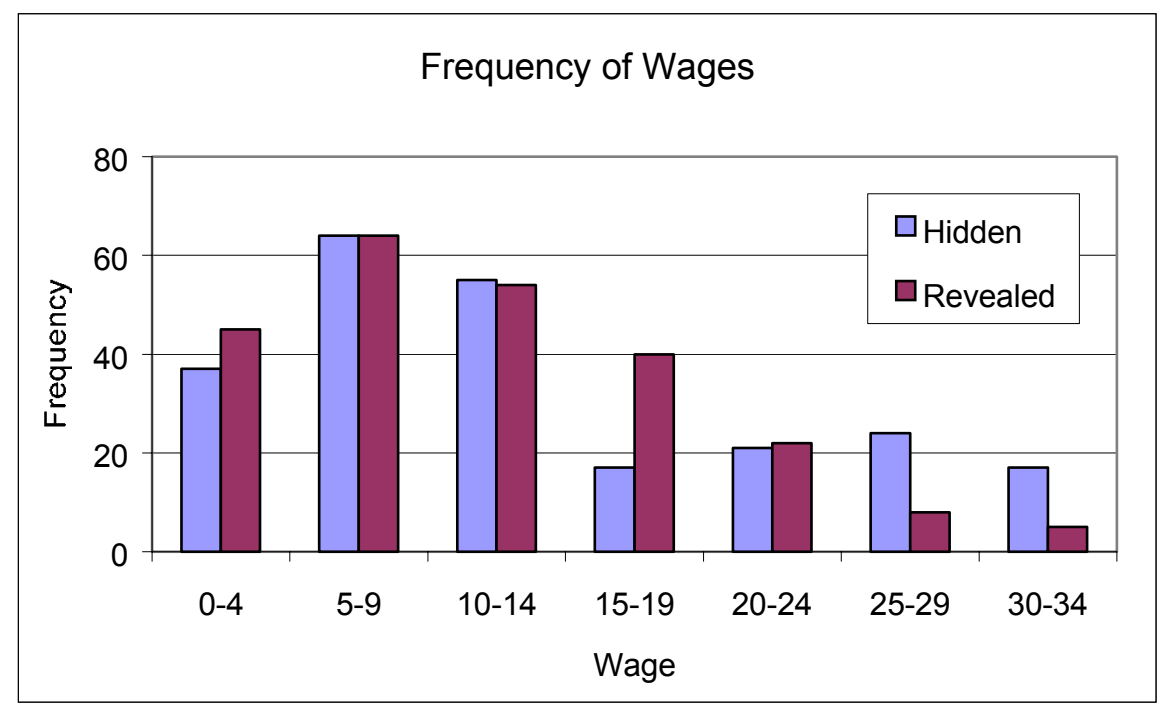

Figure 2: Frequency of Wage in both Treatments

Table 2 contains the average efforts, wages and profits in both treatments. It becomes evident that although average efforts are higher ( 8.8 instead of 8.3 ) when efforts are revealed the difference in overall average effort levels is surprisingly small. Indeed, contrary to the impression obtained for low wages in Figure 1- we cannot reject the null-hypothesis that average effort levels are the same in both treatments.

\section{Observation 3:}

Average efforts do not differ significantly between both treatments. 
Hence, although directly reciprocal behavior is significantly stronger when efforts are revealed, surprisingly there is no significant difference in effort levels. Before we proceed by taking a closer look at this "puzzle" we investigate whether the conjecture that profits are higher for the principal in the revealed effort treatment can be sustained. We can weakly reject the null hypothesis that principal's profits do not differ in favour of the alternative hypothesis that profits are larger when efforts are revealed (10\%, Mann-Whitney U-Test, one-tailed). Note that this is the case because effort levels are similar but wages tend to be higher in the hidden effort treatment. $^{9}$ Indeed, it turns out that the ratio of average effort and average wages per independent observation is significantly higher in the revealed effort treatment (5\%, Mann-Whitney U-Test, two-tailed). The average ratio across all observations in the hidden effort treatment is 0.57 whereas it is 0.79 when efforts are revealed. ${ }^{10}$

This can be illustrated by a comparison of Figures 3 and 4, which show the time series of average efforts and wages for both treatments: The "gap" between efforts and wages is larger in the hidden effort treatment. Note furthermore, that both are strongly declining in the last periods, confirming that reputation concerns indeed play a relevant role.

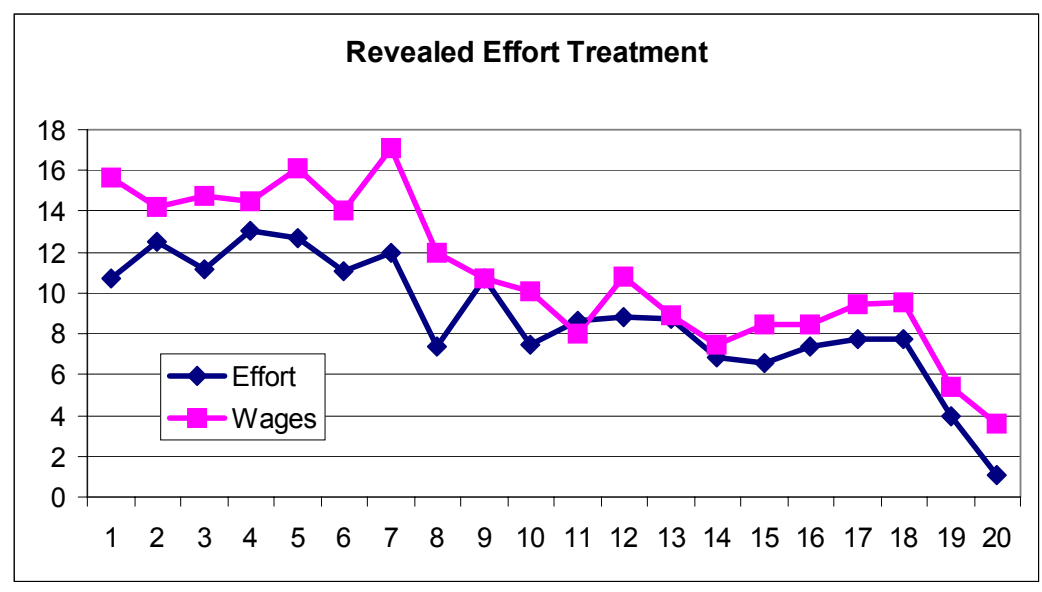

Figure 3: Average Wages and Efforts in the Revealed Effort Treatment

\footnotetext{
${ }^{9}$ However, the difference in wages is not significant.

${ }^{10}$ Median ratios are of similar size.
} 


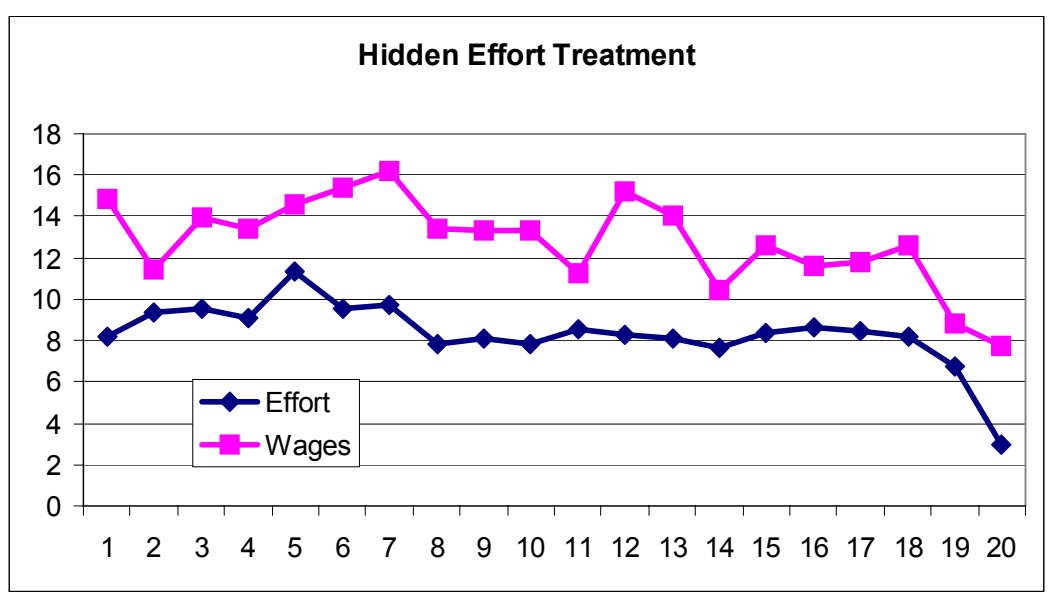

Figure 4: Average Wages and Efforts in the Hidden Effort Treatment

To understand why there is no significant difference in effort levels we have to take a closer look at individual behavior. Thus, we computed the average effort for each agent and the variance of individual average efforts for each treatment. Whereas in the revealed effort treatment this variance is only 11.1, in the hidden effort treatment it is 48.18. Hence, we find that the amount of effort chosen by the agents is much more heterogeneous in the hidden effort treatment than in the revealed effort treatment. Figure 5 shows the frequency of effort levels for both treatments.

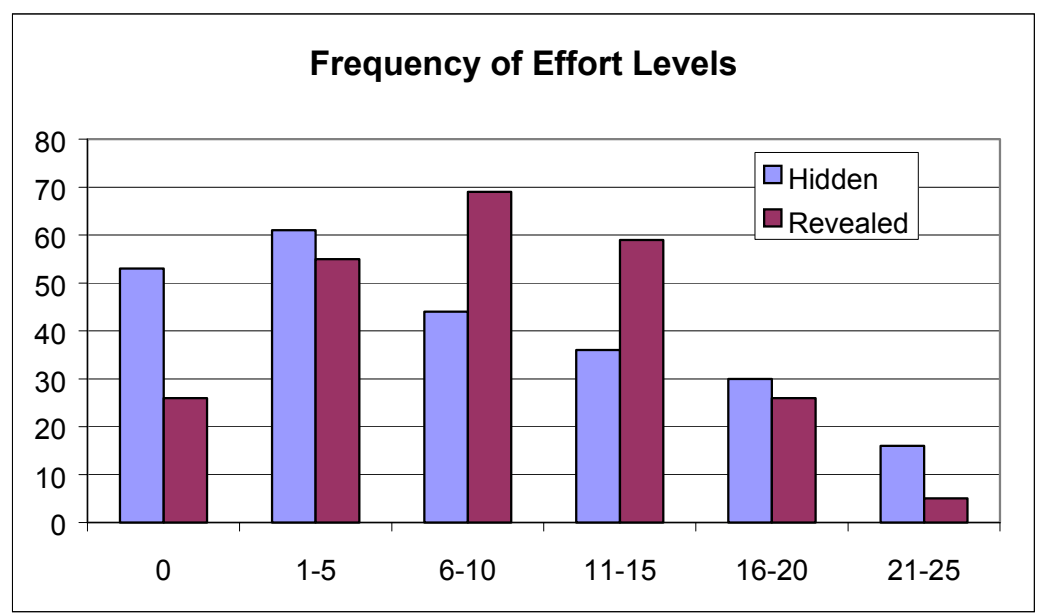

Figure 5: Frequency of Effort Levels in both Treatments

First, note that zero effort is chosen about twice as often in the hidden effort treatment compared to the situation when efforts are revealed. But effort levels 
larger than 20 are also chosen much more often when efforts remain hidden. Recall that the efficient effort level is 12 . Hence, there is a substantial proportion of agents in the hidden effort treatment choosing even more than the efficient effort level and another large fraction choosing no effort at all. The non-transparency triggers two polar patterns of behavior. On the one hand, a large fraction indeed "hides" behind the random component and still receives positive wages by the principal as she does not directly observe such behavior. On the other hand, some subjects try "desperately" to signal reciprocity by choosing an effort level that is so high that the principal can be quite sure that the agent is behaving reciprocally.

For the revealed effort setting, however, there is a larger mass of observations in the middle of the range, hence, there is much less heterogeneity in behavior in that case. We conclude:

\section{Observation 4:}

When efforts are hidden there is a larger variance in behavioral patterns. There are more agents exerting no effort at all when efforts are hidden, but also more agents show very high effort levels.

Finally, it is interesting to compare both treatments in terms of efficiency. As we have seen, the principals' profits are higher in the revealed effort treatment. However, as Table 2 shows, the average profits of the agents are higher when efforts are hidden than when efforts are revealed, which works in the opposite direction. Indeed, total profits are only slightly larger in the revealed effort treatment and we cannot reject the null-hypothesis that there is no difference in total profits. Hence, due to the diversity of reactions to the less transparent setting, there is no unambiguous effect of transparency on overall efficiency. For some agents a less transparent situation leads to a lower efficiency as it hinders the evolution of a reciprocal relationship between principal and agents. However, for other agents the opposite is true as the intransparency triggers a behavioral reaction where agents exert very high effort levels to ascertain that their "signal" of a willingness to cooperate is received by the respective principal. Note that transparency has distributional consequences: Whereas in the revealed effort treatment principals earn more than agents, the contrary is true when efforts are hidden.

\section{Conclusion}

This paper analyses the impact of transparency on the evolution of reciprocal behavior. We compare two treatments in which a principal sets a wage and the agent may respond by exerting costly effort. In the "revealed effort" treatment the principal perfectly learns both components of her payoff - the effort as well as the value of the 
random component. In the "hidden effort" treatment the principal is only informed about her payoff. Our observations indicate that transparency has an impact on the evolution of reciprocal behavior in a simple gift exchange setting. We obtained the key result that reciprocal behavior as measured by the correlation between wages and efforts is significantly stronger when efforts are directly revealed. As a consequence, it turns out that profits of principals are higher in a transparent setting.

Our results may shed some light on the question of optimal monitoring in organizations. One may think for instance of a situation where ex-ante a decision has to be taken whether to install a monitoring technology yielding precise information on an agents effort contribution. As our results indicate, a closer monitoring may not automatically imply higher effort levels as transparency had no significant impact on average effort levels in our investigation. ${ }^{11}$ However, a closer monitoring should lead to more homogeneity in agents' behavior. Whereas agents behave similarly when their efforts are revealed, very different patterns of behavior arise when efforts cannot be directly observed by principals. On the one hand, there is a large fraction of non-reciprocal agents who "hide" behind the random noise and choose very low effort levels. But on the other hand, some agents react by choosing extremely high effort levels such that their behavior can be recognized by the principal even though efforts are not directly observed. This pattern may find some analogy in casual observations from organizational practice. For instance from a large German retail chain anecdotal evidence was reported that the abolition of a working time registration system in the headquarter even led some employees to work more hours than before. A simple explanation was given that after the abolition it became harder to demonstrate ambition as working hours were no longer formally accounted for and this led the very ambitious employees to spend more hours to ascertain that their additional effort was recognized.

\section{References}

Abbink, K., Irlenbusch, B., Renner, E. (2000) "The Moonlighting Game - An Experimental Study on Reciprocity and Retribution", Journal of Economic Behavior \& Organization 42 (2), 265-277.

Berg, J., Dickhaut, J., McCabe K. (1995) "Trust, Reciprocity and Social History", Games and Economic Behavior 10, 122-142.

\footnotetext{
${ }^{11}$ Potential drawbacks of monitoring on motivation are discussed for example in Frey (1993), Griffith (1993), and Nagin, Rebitzer, Sanders, and Taylor (2002). The latter study reports a field experiment, in which a substantial proportion of employees do not respond to manipulations in the monitoring rate. Thus, like in our study, heterogenity plays a decisive role for explaining behavior in employment relationships.
} 
Bolton, G., Ockenfels, A. (2000) "ERC - A Theory of Equity, Reciprocity and Competition", American Economic Review 90, 166-193.

Brandts, J., Charness, G. (1998) "Hot versus Cold: Sequential Responses and Preference Stability in Experimental Games", Discussion Paper, Universidad Autonoma de Barcelona.

Charness, G. (2000) "Responsibility and effort in an experimental labor market", Journal of Economic Behavior and Organization 42, 375-384.

Charness, G. (forthcoming) "Attribution and Reciprocity in a simulated labor market: an experimental investigation", Journal of Labor Economics.

Charness, G., Rabin M. (2002) "Understanding Social Preferences with Simple Tests" Quarterly Journal of Economics 117, 817-869.

Clark, K., Sefton M. (2001) "The Sequential Prisoner's Dilemma: Evidence on Reciprocation", Economic Journal 111, 51-68.

Dufwenberg, M., Gneezy, U. (2000) "Measuring Beliefs in an Experimental Lost Wallet Game", Games and Economic Behavior 30, 163-182.

Dufwenberg, M., Kirchsteiger, G. (1999) "A Theory of Sequential Reciprocity", mimeo, CentER for Economic Research, Tilburg.

Dufwenberg, M., Kirchsteiger, G. (2000) "Reciprocity and Wage Undercutting", European Economic Review 44, 1069-1078.

Falk, A., Fehr, E., Fischbacher, U. (2000) "Testing Theories of Fairness - Intentions Matter", Discussion Paper University of Zurich.

Falk, A., Fischbacher, U. (1999) "A Theory of Reciprocity", Working paper No. 6, University of Zurich.

Fehr, E., Gächter, S., Kirchsteiger, G. (1997) "Reciprocity as a Contract Enforcement Device - Experimental Evidence", Econometrica 64, 833-860.

Fehr, E., Gächter, S. (2000) "Fairness and Retaliation: The Economics of Reciprocity", Journal of Economic Perspectives 14 (3), 159-181.

Fehr, E., Kirchsteiger, G., Riedl, A. (1993) "Does Fairness prevent Market Clearing? An Experimental Investigation", Quarterly Journal of Economics 108 (2), 437-460.

Fehr, E., Schmidt, K. (1999) "A Theory of Fairness, Competition, and Cooperation", Quarterly Journal of Economics 114, 817-868. 
Fischbacher, U. (1998) "Z-Tree: A Toolbox for Readymade Economic Experiments", University of Zurich.

Frey, B.S. (1993) "Does Monitoring increase work effort? The rivalry with trust and loyality", Economic Inquiry 31, 663-670.

Gächter, S., Falk, A. (2002) "Reputation and Reciprocity: Consequences for the Labor Relation", Scandinavian Journal of Economics 104 (1), 1-26.

Griffith, T.L. (1993) "Monitoring and Performance: A Comparison of Computer and Supervisor Monitoring", Journal of Applied social Psychology 23, 549-772.

Grossman, S., Hart, O. (1983) "An Analysis of the Principal-Agent Problem", Econometrica 51, 7-45.

Güth, W., Huck, S., Ockenfels, P. (1996) "Two-level ultimatum bargaining with incomplete information", Economic Journal 106, 593-604.

Hart, O., Holmström, B. (1987) "The Theory of Contracts. Advances in Economic Theory, Part 1", in: Bewley, Truman (Hrsg.), Cambridge University Press, 71-155.

Huck, S. (1999) "Responder behavior in ultimatum offer games with incomplete information", Journal of Economic Psychology 20, 183-206.

Kagel, J., Kim, C. K., Moser D. (1996) "Fairness in ultimatum games with asymmetric information and asymmetric payoffs", Games and Economic Behavior 13, 100-110.

Levine, D. (1998) "Modeling Altruism and Spitefulness in Experiments", Review of Economic Dynamics 1, 593-622.

Mitzkewitz, M., Nagel, R. (1993) "Experimental Results on Ultimatum Games with Incomplete Information", International Journal of Game Theory 22, 171-198.

Nagin, D., Rebitzer, J., Sanders, S., Taylor, L. (2002) "Monitoring, Motivation and Management: The Determinants of Opportunistic Behavior in a Field Experiment", American Economic Review 92, 850-873.

Rabin, M. (1993) "Incorporating Fairness into Game Theory and Economics", American Economic Review 83, 1281-1302.

Sappington, D. (1991) "Incentives in Principal-Agent Relationships", Journal of Economic Perspectives 5, 45-66. 
Sethi, R., Somanathan, E. (2003) "Understanding Reciprocity", Journal of Economic Behavior and Organization 50, 1-27.

Theil, H. (1971) "Principles of Econometrics", John Wiley \& Sons.

Van der Heijden, E., Nelissen, J. Potters, J., Verbon, H. (2001) "Simple and Complex Gift Exchange in the Laboratory", Economic Inquiry 39, 280-297. 


\section{Appendix: A model of transparency and inequity aversion}

Consider the following model. A principal $P$ interacts with an agent $A$ in two consecutive periods. In each period, the principal first chooses between a high and a low wage $w_{t} \in\{0,1\}$ which is directly paid to the agent. Then the agent can respond by choosing either a high or a low effort level $e_{t} \in\{0,1\}$. The costs of effort are $c(0)=0$ and $c(1)=c<1$. The principal's revenue is given by $r_{t}=k\left(e_{t}+\varepsilon_{t}\right)$, where $\varepsilon_{t} \in\{0,1\}$ is a random component where each value is drawn with probability $\frac{1}{2}$ and $\left.k \in\right] 1,2[$ is a given constant. The principal is always selfish and the agent is either selfish or inequity averse with Fehr-Schmidt type preferences, such that his utility in a given period is

$$
U_{A t}^{\text {Inequity }}=m_{A t}-\alpha \max \left\{m_{P t}-m_{A t}, 0\right\}-\beta \max \left\{m_{A t}-m_{P t}, 0\right\} .
$$

where $m_{A t}=w_{t}-c e_{t}$ and $m_{P t}=k\left(e_{t}+\varepsilon_{t}\right)-w_{t}$. We assume that the agent considers inequity only within the same period and that there is no discounting, hence, his total expected utility is $E\left[U_{A 1}\right]+E\left[U_{A 2}\right]$. A selfish agent's utility is simply $U_{A t}^{\text {selfish }}=m_{A t}$. The prior probability of meeting an inequity averse agent is given by $\tau$. Furthermore, to simplify the analysis we impose the assumptions that ${ }^{12}$ $k+c>2$ and $\tau>\frac{1}{k}$. The second assumption guarantees that the principal will have an interest to offer a high wage, when having prior beliefs on the agent's type as will become clear below.

We consider two cases: either the principal can directly observe $e_{t}$ after it has been chosen by the agent ("transparency") or she only observes $r_{t}$ ("intransparency"). As the game stops after the second period, the second period equilibrium is the same for both models given the same principal's beliefs on the agent's type. Note that the game is in both cases a signaling game as the agent may try signal his type by choosing an appropriate effort level. We have to look for perfect Bayesian equilibria of the game.

\section{The second period:}

In the second period a selfish agent always chooses $e_{2}=0$. It is straighforward to check that the agent will never choose the high effort level, when $w_{2}=0$. However, when $w_{2}=1$, an inequity averse agent has to trade-off his costs of effort against a possible loss due to inequity costs when he does not respond to the high wage with a high effort level. When he chooses $e_{2}=0$, his expected utility is

$$
\frac{1}{2}[1-\beta \max \{2-k, 0\}]+\frac{1}{2}[1-\beta \max \{2,0\}]=1+\frac{1}{2} \beta k-2 \beta .
$$

\footnotetext{
${ }^{12}$ This assumption $k+c>2$ just reduces the number of cases we have to consider. Its direct consequence is that the principal's income is higher than the agent's for both values of $\varepsilon_{t}$ when the agent has chosen the high effort level after having received the high wage.
} 
When $e_{2}=1$, it is (here we use the assumption that $k+c>2$ )

$$
\begin{aligned}
& \frac{1}{2}[1-c-\alpha \max \{2 k-2+c, 0\}]+\frac{1}{2}[1-c-\alpha \max \{k-2+c, 0\}] \\
& =1-c-\alpha\left[\frac{3}{2} k-2+c\right]
\end{aligned}
$$

Hence, he chooses $e_{2}=1$, when (2) is larger than (1) which is equivalent to

$$
\frac{c+\alpha\left(\frac{3}{2} k-2+c\right)}{2-\frac{1}{2} k}<\beta .
$$

Hence, when $\beta$ is sufficiently large the inequity averse agent will

indeed act reciprocally. Note that $\beta$ measues the extent of how the agent suffers from advantegous inequity. An agent with a high $\beta$ feels especially bad, when he is better off than the principal. If this condition is not met, even an inequity averse agent will never act reciprocally and the only equilibrium of the game will be one, where $w_{1}=w_{2}=e_{1}=e_{2}=0$. Hence, we consider now the case where this condition is met.

The principal's expected utility when he is sure to contract with an inequity averse agent and offers a wage $w_{2}=1$ is

$$
\frac{1}{2} 2 k+\frac{1}{2} k-1=\frac{3 k}{2}-1 .
$$

Now suppose that the principal believes that the fraction of inequity averse agents is $\hat{\tau}$. Hence, his expected utility when offering the high wage is

$$
\hat{\tau}\left(\frac{3 k}{2}-1\right)+(1-\hat{\tau})\left(\frac{k}{2}-1\right)=\underbrace{\frac{k}{2}}_{\text {revenue from } \varepsilon}+\underbrace{k \hat{\tau}}_{\text {expected revenue from } e}-\underbrace{1}_{\text {wage }} .
$$

When offering no wage he receives $\frac{k}{2}$. Hence, offering $w_{2}=1$ is beneficial when

$$
\frac{k+2 k \hat{\tau}}{2}-1>\frac{k}{2} \Leftrightarrow \hat{\tau}>\frac{1}{k} .
$$

\section{The first period when $e$ is directly observable:}

A perfect Bayesian equilibrium consists of the wage $w_{1}$ offered by the principal, the strategy $e_{I 1}$ choosen by the inequity averse agent in period 1 , the strategy $e_{S 1}$ chosen by the selfish agent in period 1, the principal's beliefs $\hat{\tau}_{e_{1}}$ after having observed effort level $e_{1}$. We know already the strategy played by both types of agents in period 
2 as well as the principal's strategy in period 2 for each information set: She will choose $w_{2}=1$ whenever $\hat{\tau}_{e_{1}}>\frac{1}{k}$ which will be responded by $e_{I 2}=1$ and by $e_{S 2}=0$.

The key question we have to ask is whether a pooling equilibrium exists in period 1 , such that the principal offers a high wage and both agents choose the high effort level $e_{I 1}=e_{S 1}=1$. In equilibrium the principal will then learn nothing about the agents's types and $\hat{\tau}_{1}=\tau$. As we imposed the assumption that there are sufficiently many inequity averse agents (i.e. $\tau>\frac{1}{k}$ ) she will indeed offer $w_{2}=1$. An observation of $e_{1}=0$ will only happen of the equilibrium path. We impose the most reasonable out-of-equilibrium beliefs such that $\hat{\tau}_{0}=0$ and, hence, the principal will choose $w_{2}=0$ after having observed $e_{1}=0$.

Now we have to check, whether indeed both types choose the high effort level in period 1 after having received a high wage. An inequity averse agent will clearly always do that as it raises his first and second period utility as has been shown above. A selfish agent knows that he will receive $w_{2}=1$ if and only if he chooses the high effort level. But as $c<1$ he will always do that. Hence, there is always a pooling equilibrium in which both agents choose the high effort level in the first period when the principal has chosen $w_{1}=1 .{ }^{13}$

Note that - by the same reasoning - we cannot have a separating equilibrium: A selfish agent will never want to reveal himself as he can always gain $w_{2}=1$ by "imitating" the inequity averse agent. We get the following result:

Proposition 1 In the transparent situation there will always be a pooling equilibrium in which both agents choose the high effort level in the first period after having received the high wage and there will never be a separating equilibrium where only the inequity averse agents choose the high effort level.

\section{The first period when $e$ is not directly observable:}

Now the information structure is different. Instead of beliefs for each of both effort levels now we have to specify beliefs $\hat{\tau}_{r_{1}}$ for each possible level of the principal's revenue $r_{1}$ as this is the only observable variable. Note that $r_{1}$ can take three different levels (either $0, k$ or $2 k$ ) depending on the chosen effort level and the realization of $\varepsilon_{1}$.

Lets again suppose that a pooling equilibrium exists in which both agents choose the high effort level after the high wage. Note that in that case $r_{1}$ can take values $k$

\footnotetext{
${ }^{13}$ The principal will have an interest to offer $w_{1}=1$ instead of $w_{1}=0$. Suppose that the principal offers zero wage in period 1. This may only be attractive if an inequity averse agent responds by a high effort level in the first period to signal his type. However, this signaling is of no use. When choosing an effort level of zero in the first period an agent nonetheless receives a high wage in the second: As we have seen, this is the principal's optimal strategy when he has learned nothing on the agent's type.
} 
or $2 k$ on the equilibrium path and in both cases the principal's beliefs are equal to his prior beliefs. A realization of $r_{1}=0$ can only happen off the equilibrium path. It will be easiest to sustain such an equilibrium with the reasonable beliefs $\tau_{0}=0$, which imply that the principal will never offer a high wage after observing the lowest revenue. Again, it will indeed be optimal for the inequity averse agent to choose $e_{1}=1$ in this equilibrium as otherwise he would be worse off in the first as well as in the second period. A selfish agent again anticipates that he will earn the high wage for sure when choosing the high effort level as the revenue will then at least be $k$. However, when he deviates and chooses $e_{1}=0$ still $r_{1}=k$ is realized with probability $\frac{1}{2}$, which will be followed by a high wage offer in this pooling equilibrium. Hence, he prefers to deviate from the proposed equilibrium strategy if

$$
0+\frac{1}{2}>-c+1 \Leftrightarrow c>\frac{1}{2}
$$

Hence, in contrast to the transparent situation, a pooling equilibrium in which both types choose the high effort level will not exist if the costs of high effort are relatively high.

But here a separating equilibrium may exist in which $e_{I 1}=1$ and $e_{S 1}=0$ : In that case the principal knows (on the equilibrium path) that the agent is selfish if he observes $r_{1}=0$ and again $\tau_{0}=0$. A revenue of size $r_{1}=1$ can be due to either a (lucky) selfish or an (unlucky) inequity averse agent. In that case the principal's posterior beliefs are

$$
\tau_{1}=\frac{P(A \text { inequity averse } \mathscr{G} r=1)}{P(r=1)}=\frac{\tau \frac{1}{2}}{\tau \frac{1}{2}+(1-\tau) \frac{1}{2}}=\tau .
$$

However, when $r_{1}=2$ she knows for sure that the agent is inequity averse and $\tau_{2}=1$. Hence, as above the principal will offer a high wage if and only if $r_{1} \in\{k, 2 k\}$ and a low wage if $r_{1}=0$. And again the selfish agent will indeed want to choose the low effort level in the first period if $c>\frac{1}{2}$ and we can conclude:

Proposition 2 In the intransparent situation a pooling equilibrium in which both types choose the high effort level in the first period will only exist when $c \leq \frac{1}{2}$. For $c \geq \frac{1}{2}$ a separating equilibrium exist in which only the inequity averse agents chooses the high effort level.

Hence, indeed a reduced transparency makes it less attractive for the selfish agents to imitate reciprocal behavior. Due to the imperfect observability they may get away with a high wage offer in the second period even after a low effort in the first. 
Appendix: Raw data in the hidden effort treatment
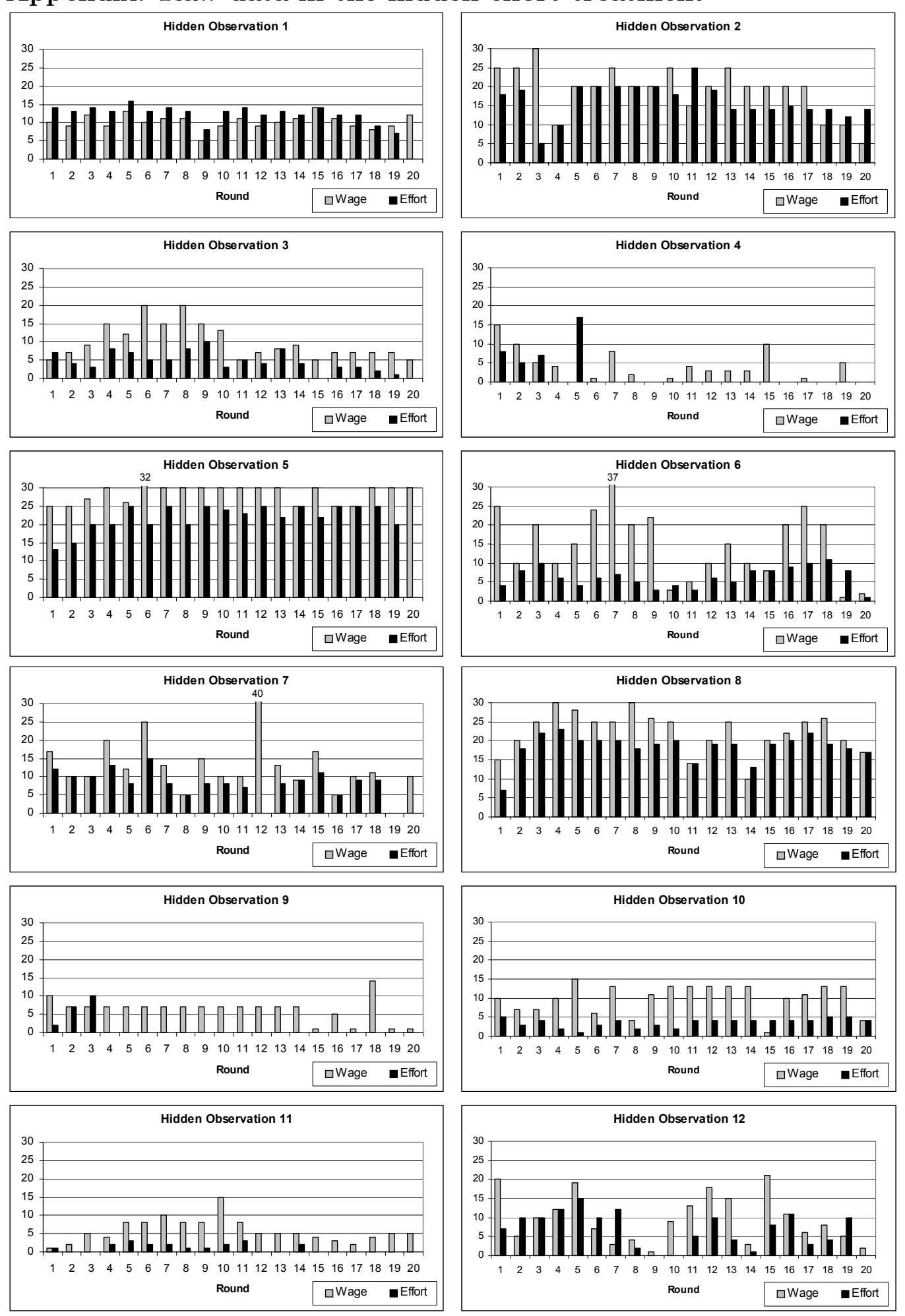
Appendix: Raw data in the revealed effort treatment
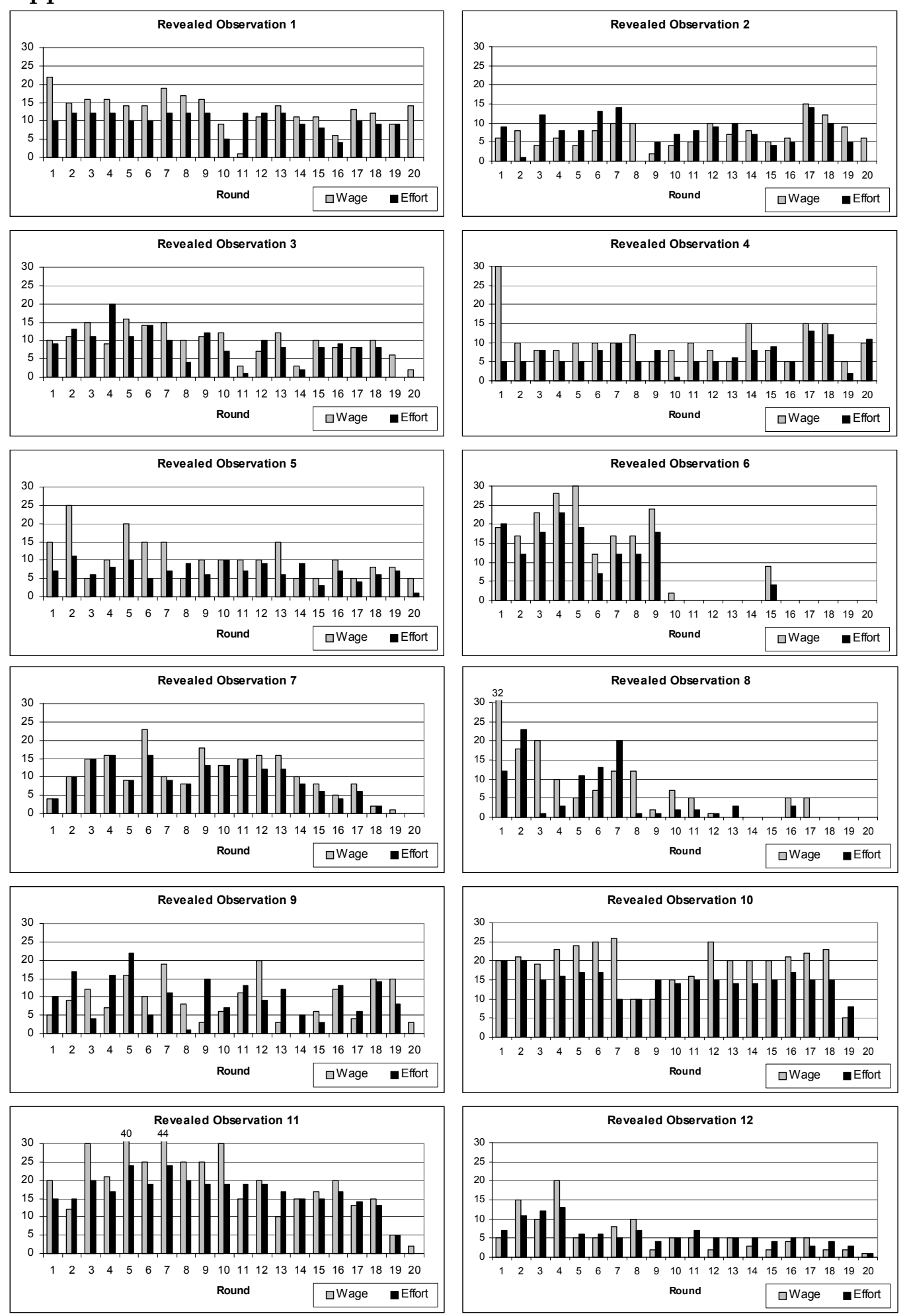


\section{Appendix: Experimental Instructions}

(original instructions were in German; they are available upon request from the authors; treatment differences in instructions are indicated by \{hidden effort treatment. "..."; revealed effort treatment: “..."\})

\section{Periods and Rounds}

- The experiment consists of 20 periods.

- During the experiment you belong to a group of 2 members, including yourself. You do not know the identity of the other member. The composition of each group does not change throughout the experiment.

- There are two different roles, a type A-player and a type B-player. The different roles are assigned at random in the beginning and do not change during the experiment.

\section{The Structure of a Period}

\section{- Offer of transfer payments by the player of type $A$}

- At the beginning of each period, the A-type player announces a transfer in the fictitious currency "Taler" to the player of type B, i.e. he specifies an integer out of the set $\{0, \ldots, 45\}$.

- This transfer is implemented immediately, i.e. the determined amount is transferred from the type A-player and credited to the type-B player.

\section{- Selection of a number by the player of type B}

- After the transfer has occurred, the player of type-B has to select a number out of the integer set $\{0, \ldots, 25\}$. The larger the chosen number, the higher the costs the type-B player has to bear (see table of costs).

- After the selection of this number, the respective costs are subtracted (in "Taler") from the account of the type-B player.

- At the same time the computer determines a random number out of the integer set $\{0, \ldots, 20\}$, whereby each of these numbers can be chosen with same probability.

- The so-called result is calculated as follows: result = selected number + random number. This result is credited to the account of the type A-player (in "Taler").

- $\quad \quad$ hidden effort treatment. "Note, that only the result is revealed to the type A-player. Thus, he does not know precisely, which number was selected by the type B-player and which random number was chosen."; revealed effort treatment. "Note, that both components of the result are revealed to the type A-player. Thus, he knows precisely, which number was selected by the type B-player and which random number was chosen."

- Note, that the type B-player only has to pay the costs of his selected number. The random number causes no costs.

- After publication of the results the period is at the end and a new one will be started.

\section{Initial Capital and Total Payoffs}

- At the beginning of the experiment, every participant receives a certain amount as the initial capital in the fictitious currency "Taler" on his amount. At the end of the experiment, his total account will be changed into DM at an exchange rate of 1,50 DM per 100 Taler and will be paid to the player.

\section{Please note:}

- During the experiment no communication is permitted - except via the experimental software.

- All decisions are made anonymously, i.e. no one gets to know the identity of someone else who has made a certain decision.

- In addition the final payment is made anonymously, i.e. nobody learns, how much another participant has earned. 


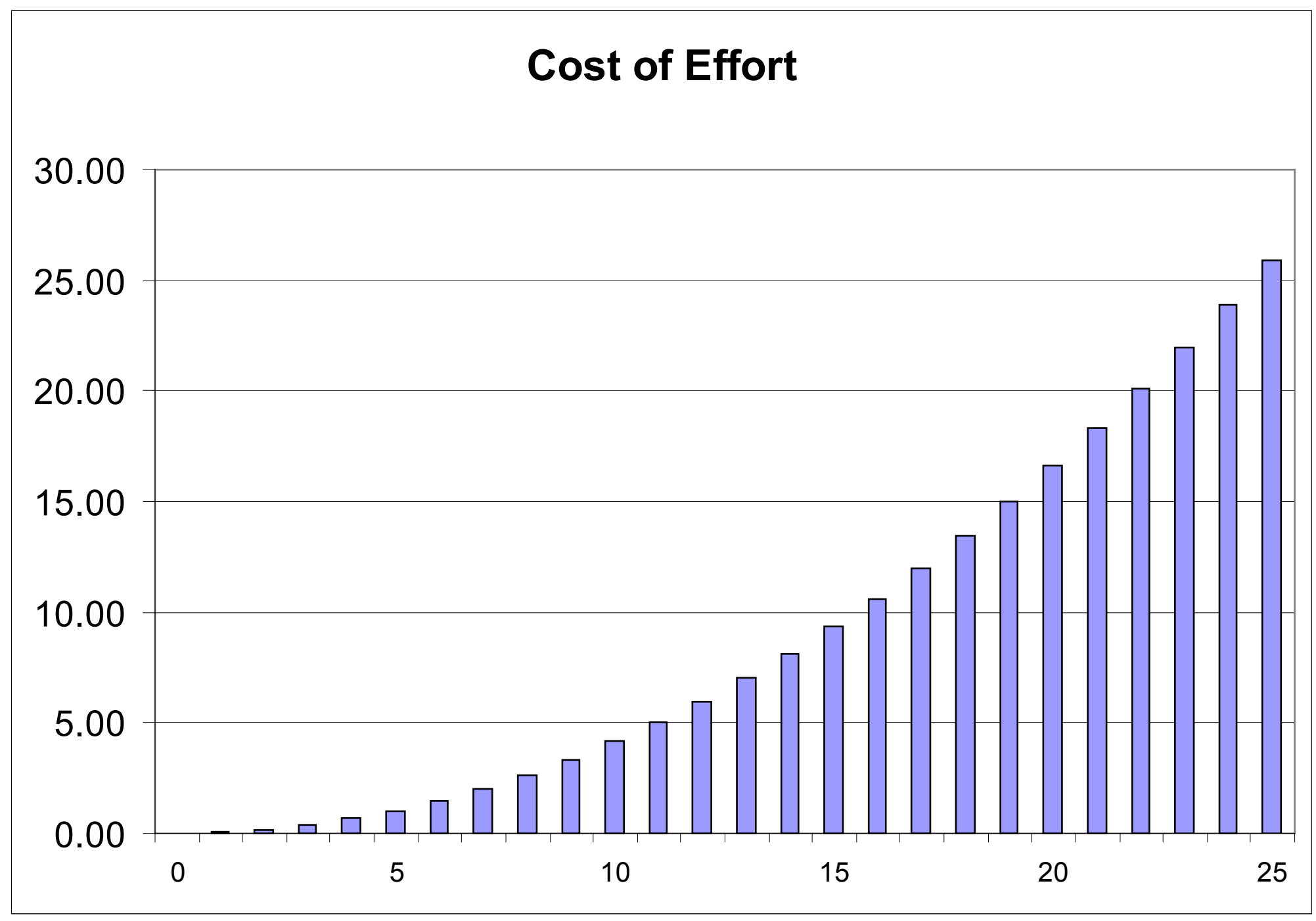

\begin{tabular}{|l|r|r|r|r|r|r|r|r|r|r|r|r|r|r|r|r|r|r|r|r|r|r|r|r|r|r|r|}
\hline Effort & 0 & 1 & 2 & 3 & 4 & 5 & 6 & 7 & 8 & 9 & 10 & 11 & 12 & 13 & 14 & 15 & 16 & 17 & 18 & 19 & 20 & 21 & 22 & 23 & 24 & 25 \\
\hline Cost & 0.00 & 0.04 & 0.17 & 0.37 & 0.66 & 1.04 & 1.49 & 2.03 & 2.66 & 3.36 & 4.15 & 5.02 & 5.98 & 7.01 & 8.13 & 9.34 & 10.62 & 11.99 & 13.45 & 14.98 & 16.60 & 18.30 & 20.09 & 21.95 & 23.90 & 25.94 \\
\hline
\end{tabular} 


\section{IZA Discussion Papers}

\begin{tabular}{|c|c|c|c|c|}
\hline No. & Author(s) & Title & Area & Date \\
\hline 873 & $\begin{array}{l}\text { M. Falk } \\
\text { B. M. Koebel }\end{array}$ & $\begin{array}{l}\text { The Impact of Office Machinery and Computer } \\
\text { Capital on the Demand for Heterogeneous } \\
\text { Labour }\end{array}$ & 5 & $09 / 03$ \\
\hline 874 & J.-S. Pischke & $\begin{array}{l}\text { The Impact of Length of the School Year on } \\
\text { Student Performance and Earnings: Evidence } \\
\text { from the German Short School Years }\end{array}$ & 6 & $09 / 03$ \\
\hline 875 & C. Grund & $\begin{array}{l}\text { Severance Payments for Dismissed Employees } \\
\text { in Germany }\end{array}$ & 3 & $09 / 03$ \\
\hline 876 & $\begin{array}{l}\text { M. Karanassou } \\
\text { H. Sala } \\
\text { D. J. Snower }\end{array}$ & $\begin{array}{l}\text { The European Phillips Curve: Does the NAIRU } \\
\text { Exist? }\end{array}$ & 3 & $09 / 03$ \\
\hline 877 & M.-S. Yun & Decomposing Differences in the First Moment & 3 & 09/03 \\
\hline 878 & $\begin{array}{l}\text { J. T. Addison } \\
\text { C. Schnabel } \\
\text { J. Wagner }\end{array}$ & $\begin{array}{l}\text { The Course of Research into the Economic } \\
\text { Consequences of German Works Councils }\end{array}$ & 3 & $09 / 03$ \\
\hline 879 & $\begin{array}{l}\text { A. Constant } \\
\text { Y. Shachmurove }\end{array}$ & $\begin{array}{l}\text { Entrepreneurial Ventures and Wage Differentials } \\
\text { Between Germans and Immigrants }\end{array}$ & 1 & $09 / 03$ \\
\hline 880 & $\begin{array}{l}\text { W. Koeniger } \\
\text { A. Vindigni }\end{array}$ & $\begin{array}{l}\text { Employment Protection and Product Market } \\
\text { Regulation }\end{array}$ & 2 & $10 / 03$ \\
\hline 881 & R. A. Hart & $\begin{array}{l}\text { Worker-Job Matches, Job Mobility, and Real } \\
\text { Wage Cyclicality }\end{array}$ & 1 & $10 / 03$ \\
\hline 882 & $\begin{array}{l}\text { A. Lindbeck } \\
\text { D. J. Snower }\end{array}$ & The Firm as a Pool of Factor Complementarities & 5 & $10 / 03$ \\
\hline 883 & $\begin{array}{l}\text { S. Groeneveld } \\
\text { J. Hartog }\end{array}$ & $\begin{array}{l}\text { Overeducation, Wages and Promotions within } \\
\text { the Firm }\end{array}$ & 5 & $10 / 03$ \\
\hline 884 & $\begin{array}{l}\text { J. Masso } \\
\text { A. Heshmati }\end{array}$ & $\begin{array}{l}\text { The Optimality and Overuse of Labour in } \\
\text { Estonian Manufacturing Enterprises }\end{array}$ & 4 & $10 / 03$ \\
\hline 885 & $\begin{array}{l}\text { A. Constant } \\
\text { K. F. Zimmermann }\end{array}$ & $\begin{array}{l}\text { The Dynamics of Repeat Migration: A Markov } \\
\text { Chain Analysis }\end{array}$ & 1 & $10 / 03$ \\
\hline 886 & $\begin{array}{l}\text { J. J. Dolado } \\
\text { M. Jansen } \\
\text { J. F. Jimeno }\end{array}$ & $\begin{array}{l}\text { On-the-Job Search in a Matching Model with } \\
\text { Heterogenous Jobs and Workers }\end{array}$ & 1 & $10 / 03$ \\
\hline 887 & $\begin{array}{l}\text { B. Irlenbusch } \\
\text { D. Sliwka }\end{array}$ & $\begin{array}{l}\text { Transparency and Reciprocal Behavior in } \\
\text { Employment Relations }\end{array}$ & 7 & $10 / 03$ \\
\hline
\end{tabular}

An updated list of IZA Discussion Papers is available on the center's homepage www.iza.org. 